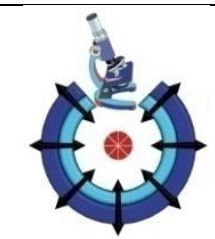

ASRT

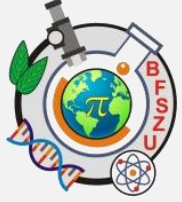

Bulletin of Faculty of Science - Zagazig University

https://bfszu.journals.ekb.eg

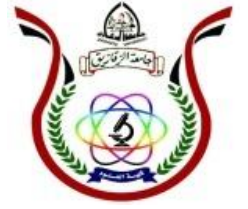

FS-ZU

\title{
Gamma Ray Attenuation Parameters of Some Boro-Silicate Glasses Doped Mixed Heavy Metal ions
}

\author{
I.I. Bashter ${ }^{1}$, S.M. Salem², S.F. Mansour ${ }^{1,3}$, M.S. Sadeq ${ }^{1,4}{ }^{,}$, A.G. Mostafa ${ }^{2}$ and H. A. Saudi ${ }^{5}$ \\ ${ }^{1}$ Phys. Dept., Faculty of Science, Zagazig Univ., Zagazig, Egypt. \\ 2Phys. Dept., Faculty of Science, Al-Azhar Univ., Nasr city, Cairo ,Egypt. \\ ${ }^{3}$ Phys. Dept., Faculty of Science, king Abdulaziz Univ., Jeddah, Saudi Arabia. \\ ${ }^{4}$ Basic sciences Dept., Faculty of Engineering Science, Sinai Univ., Al-Arish, Egypt. \\ ${ }^{5}$ Physics Department, Faculty of Science, Al-Azhar University, Girls Branch, Nasr City, Cairo, Egypt
}

\section{ARTICLE HISTORY}

Received: 1 May 2018

Revised: 20 March 2018

Accepted: 1 July 2018

\section{KEY WORDS}

Barium-Bismuth-Boro-

Silicate Glasses

Half Value Layer

Mass Attenuation

Coefficient

Mean Free Path

\begin{abstract}
The attenuation of gamma-ray radiation depends mainly on the energy of the incident gamma photon, the effective atomic number, density of the elements in the shielding material and the thickness of such shield. However, in this work, mass and linear attenuation coefficients, effective atomic number and electron density, mean free paths, half value layer and $10^{\text {th }}$ value layer of some barium-bismuth-boro-silicate glasses were obtained at gamma-ray photon energies of $0.662,1.173$ and $1.332 \mathrm{MeV}$, by using Win-XCOM computer program. The obtained data were then compared with the experimental data. The obtained theoretical results were found in good agreement with these obtained experimentally. According to the obtained results, it can be stated that, Boro-silicate glasses containing mixed heavy metal oxides $\left(\mathrm{BaO}\right.$ and $\mathrm{Bi}_{2} \mathrm{O}_{3}$ ) appeared to be transparent and have good gamma-ray shielding properties. But the best glass sample that can act as good attenuator is that containing $25 \mathrm{~mol} \% \mathrm{Bi}_{2} \mathrm{O}_{3}$, at low gamma-ray energy photons.
\end{abstract}

*Corresponding Author: mhmd_sa3d@hotmail.com

\section{INTRODUCTION}

Glasses appeared now of special interest because they are optically transparent and easy manufactured. Therefore gamma-ray attenuation parameters have been thoroughly investigated for various types of glasses specially those containing heavy metal ions (HMIs)
[(Abdel_Ghany et al. 2015),(Bagheri et al., 2016), (Kaewjaeng et al.,2012), (Chahine et al., 2004), (Kirdsiri et al., 2011)]. Among various glass types, boro-silicate glasses represent an interesting glass family in the field of glass science. These glasses are characterized by their 
low thermal expansion coefficients, resistance to thermal shock and ability for transmitting visible light. The addition of some HMIs (as bismuth or barium), promotes these gamma ray shielding properties [(Zoulfakar et al., 2017), Chanthima et al., 2013), (Kaur et al., 2016)]. According to a quick review of literatures, it is easy to observe that many articles have been published concerning with the study of the attenuation parameters of various glasses containing single HMI, but what about the attenuation parameters if two different HMIs are introduced in a glass network?.

However, the effect introducing two mixed HMIs (bismuth \& barium) on the structure and the nuclear shielding parameters of some borosilicate glasses will be thoroughly investigated. The molecular composition of the supposed glasses are $\left[20 \% \mathrm{SiO}_{2}+54 \% \mathrm{~B}_{2} \mathrm{O}_{3}\right.$ $\left.+1 \% \mathrm{NiO}+\mathrm{x} \% \mathrm{Bi}_{2} \mathrm{O}_{3}+(25-\mathrm{x}) \mathrm{BaO}\right], \mathrm{x}=5,10$, 15, 20 and 25. Win-XCom program was applied at different gamma rays energies to determine of radiation shielding parameters of the supposed glass system. The obtained results were compared with the available experimental data to achieve asuitable shielding glass and the most appropriate composition required for a particular application.

\section{EXPERIMENTAL WORK}

Glasses of the molecular composition, [20\% $\mathrm{SiO}_{2}+54 \% \mathrm{~B}_{2} \mathrm{O}_{3}+1 \% \mathrm{NiO}+\mathrm{x} \% \mathrm{Bi}_{2} \mathrm{O}_{3}+(25-$ $\mathrm{x}) \mathrm{BaO}], \mathrm{x}=5,10,15,20$ and 25, have been prepared by the melt quenching method. Pure

\section{RESULTS AND DISCUSSION}

\section{1. X-Ray diffraction}

The samples under study were examined visually, where they all appeared to be transparent and free of cracks, air bubbles and inhomogeneity, that is they appeared in pure amorphous state. In spite of this, XRD analysis was applied here to confirm the amorphous nature of the prepared samples. However, Fig. 1 shows the XRD patterns of the samples in which $\mathrm{x}=5$ and $25 \quad \mathrm{Bi}_{2} \mathrm{O}_{3}$ respectively, as grade silicon dioxide $\left(\mathrm{SiO}_{2}\right)$, boric acid $\left(\mathrm{H}_{3} \mathrm{BO}_{3}\right)$, barium carbonate $\left(\mathrm{BaCO}_{3}\right)$, nickel oxide $(\mathrm{NiO})$ and bismuth oxide $\left(\mathrm{BiO}_{3}\right)$ were used to prepare the glass batches to yield $30 \mathrm{~g}$ glass samples. The batches were mixed and ground well in an agate mortar. They were then placed in porcelain crucibles and were melted in an electric muffle furnace at $1200{ }^{\circ} \mathrm{C}$ for $2 \mathrm{hrs}$. Melts were stirred several times during melting, in order to obtain homogenous glass samples. Then they were casted onto a copper molds to obtain the desired solid samples.

X-Ray diffraction patterns were recorded at room temperature with $2 \mathrm{q}$ between $4^{\circ}$ and $90^{\circ}$, using a SHIMADZU 6000,X-Ray Diffractometer, outfitted with copper target $(\lambda=$ $1.542 \mathrm{~A}^{0}$ ), operating at $40 \mathrm{kV}$ and $30 \mathrm{~mA}$.

Density measurements were carried out applying Archimedes's principle, byusing $\mathrm{CCl}_{4}$ as an emersion liquid and an electric balance with accuracy of 4-decimal digits. The molar volume values were then calculated by using the obtained density values.

Attenuation coefficients of the prepared glassesb were measured in narrow beam transmission geometry by using $\mathrm{NaI}$ (TI) crystal detector with energy resolution of $12.5 \%$ at 662 $\mathrm{keV}$, in conjunction with multi-channel analyzer (MCA). ${ }^{60} \mathrm{Co}$ and ${ }^{137} \mathrm{Cs}$ radioactive sources were used to radiate different gamma-ray photon energies. The intensities of the incident and transmitted photons of the used gamma ray energies were measured on the MCA for a fixedtime by selecting a symmetrical narrow region with respect to the centroid of the photon peak (Ahmed et al., 2015).

representative patterns. It is seen that, there are only humps in between $2 q=20$ and $35^{\circ}$, with no any sharp peaks (due to any crystalline phase) in all samples. Doubtless, this confirms directly the amorphous nature and randomness character (glassy phase) of all the studied samples.

Fig. 1: XRD of the glass samples containing 5and $25 \mathrm{~mol} \%$ as representative curves.

\section{2. Density and molar volume}




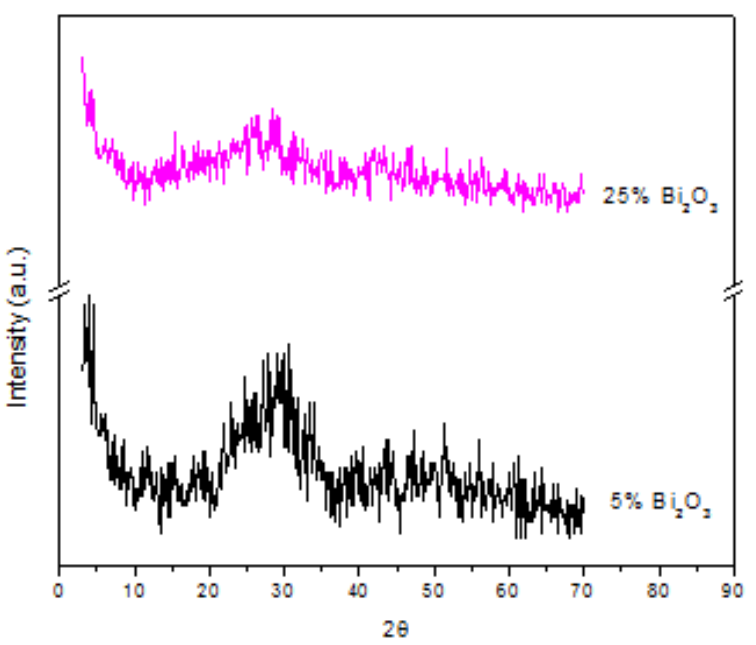

The density ( $\rho$ ) of the studied glasses was measured using Archimedes's principle, and the obtained values are depicted in Fig. 2 as a function of $\mathrm{Bi} 2 \mathrm{O} 3$. It is observed that, with the increase of $\mathrm{Bi} 2 \mathrm{O} 3$ content, the density show gradual linear increase. Such increase may be due to the replacement of $\mathrm{BaO}$ (of lighter molecular weight $(153.34 \mathrm{~g} / \mathrm{mol}$ )) by Bi2O3 (of heavier molecular weight $(465.96 \mathrm{~g} / \mathrm{mol}))$ in the glass network which leads logically to increase the density of the studied glasses.

Fig. 2: The change of density versus $\mathrm{Bi}_{2} \mathrm{O}_{3}$ content.

Thereafter, by the aid of the obtained density

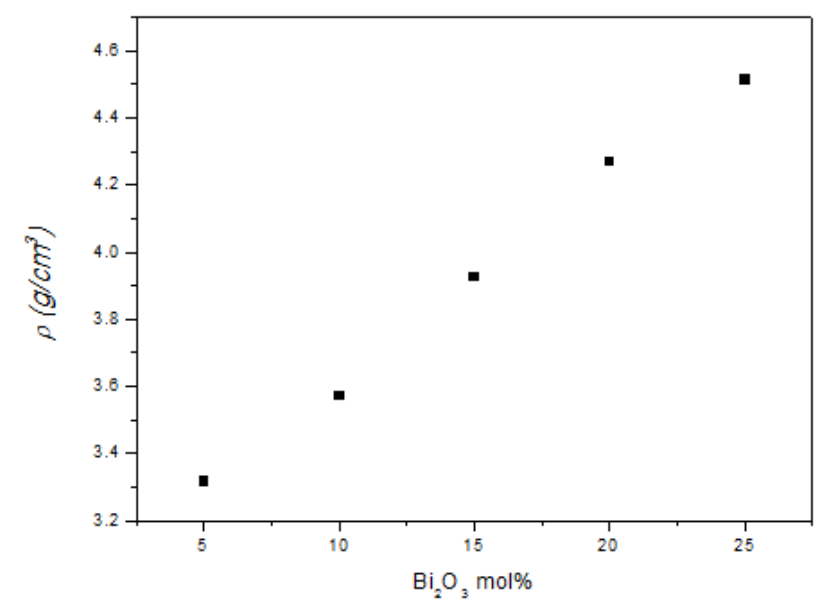

values, the molar volume $\left(\mathrm{V}_{\mathrm{m}}\right)$ values were calculated and its variation is exhibited in Fig. (3) as a function of $\mathrm{Bi}_{2} \mathrm{O}_{3}$ content.

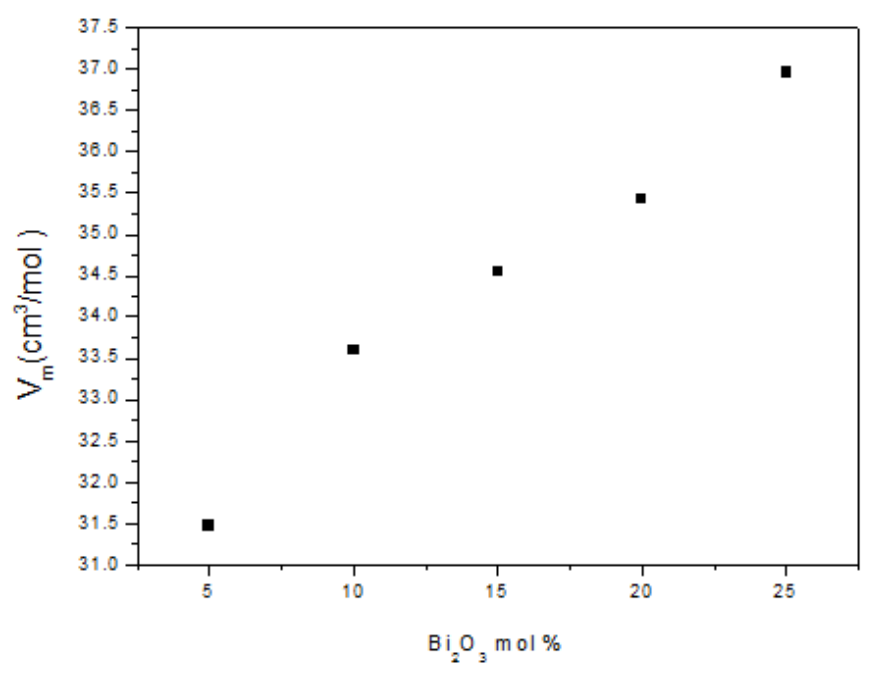

Fig. (3): The change of the molar volume versus

$$
\mathrm{Bi}_{2} \mathrm{O}_{3} \text { content. }
$$

The It is observed that as $\mathrm{Bi}_{2} \mathrm{O}_{3}$ content was gradually increased, $\mathrm{V}_{\mathrm{m}}$ shows gradual linear increase. Such increase in the molar volume may be due to the following factors:

- $\quad$ The gradual increase in the number of oxygen anions in the glass network, where one oxygen $(\mathrm{BaO})$ is replaced by three oxygen anions $\left(\mathrm{Bi}_{2} \mathrm{O}_{3}\right)$.

- The gradual increase of the positive cations where, only single barium cations is replaced by two bismuth cations. In addition to the differences in their ionic radii of both cations where, the ionic radius of $\mathrm{Bi}^{+3}$ equals $1.2 \mathrm{~A}^{\mathrm{o}}$ while the ionic radius of $\mathrm{Ba}^{+2}$ equals $1.35 \mathrm{~A}^{\circ}$.

The gradual increase of $V_{m}$ can be taken as evidence for the increase of the number of vacancies in the network.

\subsection{Linear and Mass attenuation}

\section{Coefficients}

The linear attenuation coefficient $\left(\mathrm{m}_{\mathrm{l}}\right)$ values were measured experimentally, while the mass attenuation coefficient $\left(\mathrm{m}_{\mathrm{m}}\right)$ values were calculated by dividing the linear attenuation coefficient by the density of a sample. Also the linear and mass attenuation coefficient values were calculated theoretically for the gammaphoton energies of interest by using Win- 
XCOM program. The variations of both coefficients are depicted in Figs (4 and 5) respectively as a function of $\mathrm{Bi}_{2} \mathrm{O}_{3}$ content. It is observed from both figures that the values of the linear and mass attenuation coefficient values increased as $\mathrm{Bi}_{2} \mathrm{O}_{3}$ content was increased. This increase may be due to the high atomic weight of bismuth $(\mathrm{Bi}=208.98 \mathrm{~g} / \mathrm{mol})$ when compared with that of barium $(\mathrm{Ba}=137.34 \mathrm{~g} / \mathrm{mol})$. It is also observed that, such increase is more intense at low gamma-ray energies than at high energies which may be due to the process of photoelectric effect, that is usually preferable with high-atomic-number absorbers and low photons energies.

It can be observed that, both the experimental and the theoretical linear attenuation coefficient values appeared to be approximately coincident.
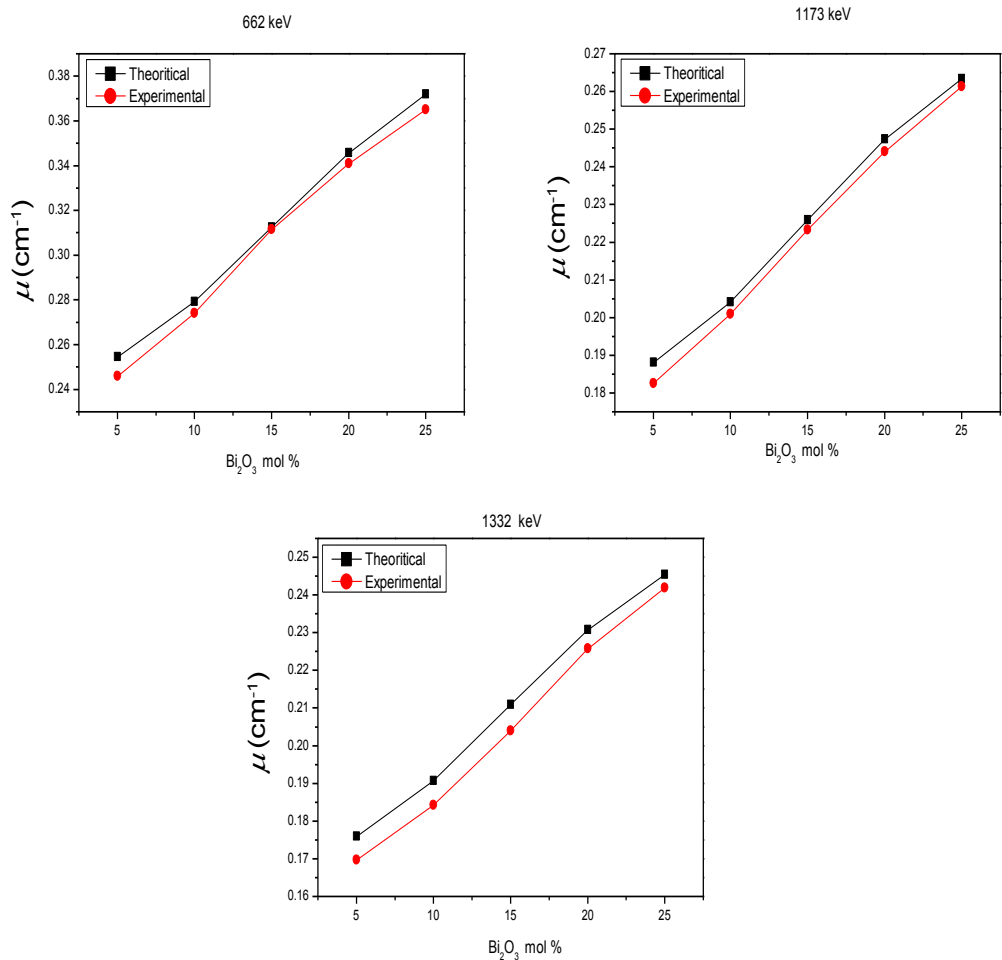

Fig. 4: The change of the linear attenuation coefficient $\left(\mathrm{m}_{1}\right)$ at various photon energies versusBi2 $\mathrm{O}_{3}$ content. 

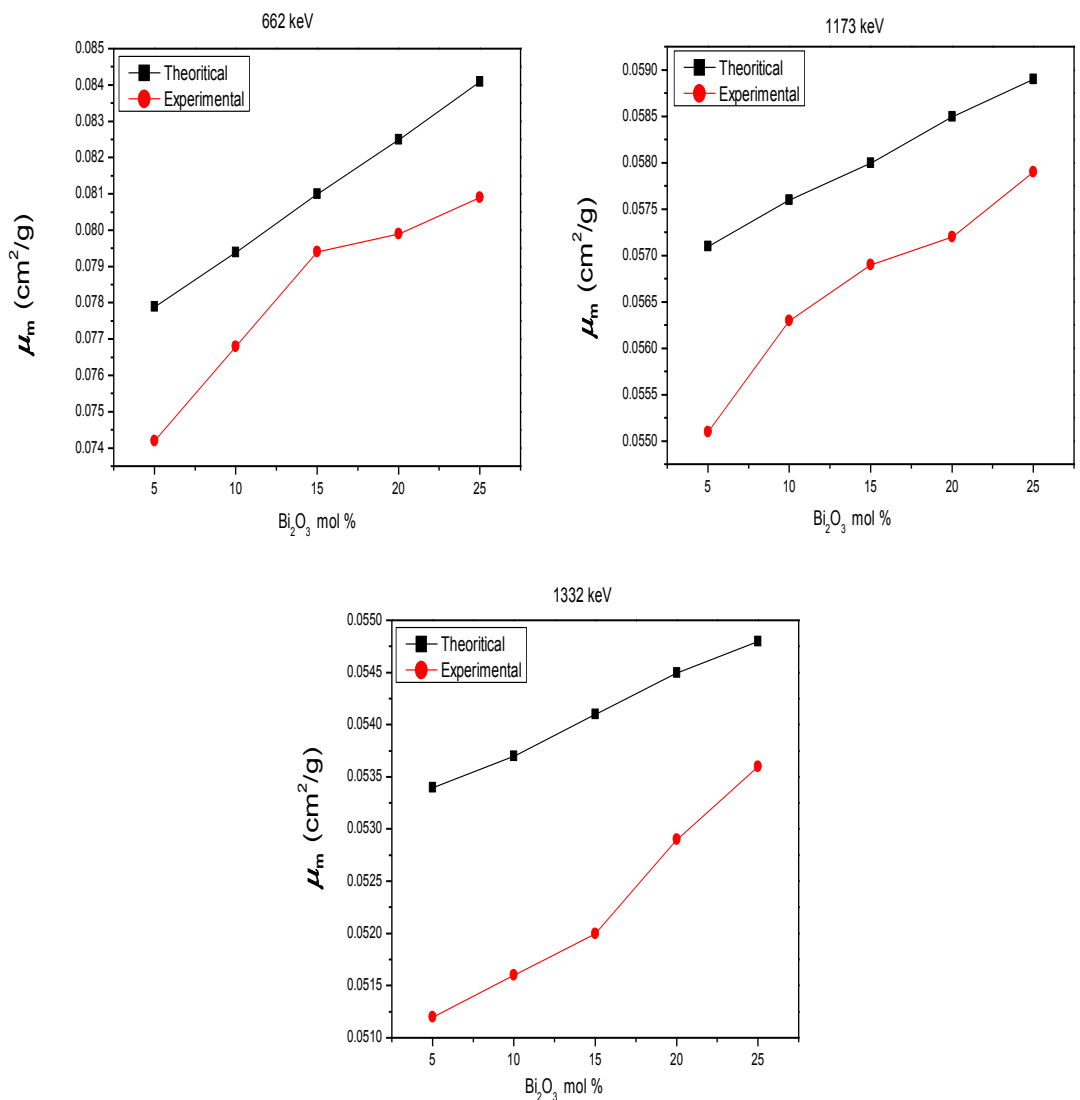

Fig. (5): The change of the mass attenuation coefficient $\left(\mathrm{m}_{\mathrm{m}}\right)$ at various photon energies versus

$\mathrm{Bi}_{2} \mathrm{O}_{3}$ content.

\section{4. The half value layer (HVL)}

The HVL is used to describe the effectiveness of gamma-ray shielding material (Manohara et al., 2009).The calculated values of HVL are depicted in Fig. (6). It is observed that the obtained HVL decreased with increasing $\mathrm{Bi}_{2} \mathrm{O}_{3}$ content in the studied glasses. Such decrease of HVL can be attributed to the increase in density and mass attenuation coefficient of the studied glasses with increasing $\mathrm{Bi}_{2} \mathrm{O}_{3}$ content. 

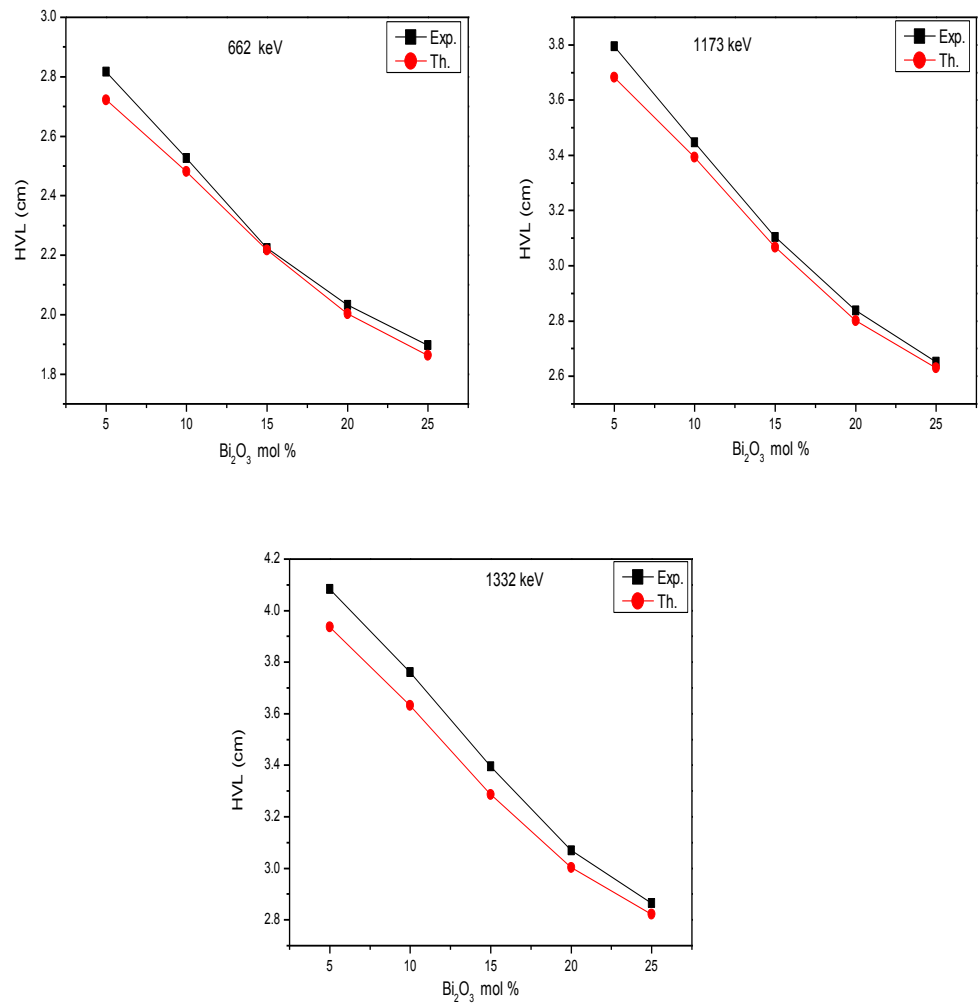

Fig. 6: The change of $\mathrm{HVL}$ at various photon energies versus $\mathrm{Bi}_{2} \mathrm{O}_{3}$ content.

\section{Conclusion}

According to the investigated gamma-ray shielding parameters of some barium-bismuth-boro-silicate glasses (glasses under study) at different energies of gamma rays $(662 \mathrm{keV}, 1,173 \mathrm{keV}$, and 1,332 keV) using Win-XCOM program and the available experimental measurements it can be concluded that, as $\mathrm{Bi}_{2} \mathrm{O}_{3}$ was gradually increased.

1- Both the obtained experimental and theoretical results are compared with each other were they show approximately good agreement.

2- The prepared glasses having mixed heavy metal cations can be used as radiation shielding materials. Specially at low gamma-ray photon energies.

\section{REFERNCES}

1. Abdel_Ghany A.M., Zoulfakar A. M., Abou-Elnasr T. Z., Hassaan M. Y. and Mostafa A. G., Blast Furnace Slag as a Raw Material to Manufacture Gamma-Ray Transparent Shield
3- It was found that the samples with high bismuth oxide content have higher density, consequently higher mass attenuation coefficient and low HVL.

4- The calculated $\mathrm{V}_{\mathrm{m}}$ shows also gradual increase due to the difference between the atomic radii of both $\mathrm{Bi}$ and $\mathrm{Ba}$ as well as due to the gradual increase of oxygen anions in the glass networks.

5- It is concluded also that, the attenuation parameters $\left(\mathrm{m}_{1} \& \mathrm{~m}_{\mathrm{m}}\right)$ of a sample increased with $\mathrm{Bi}_{2} \mathrm{O}_{3}$ content, while they decreased with the increase of gamma-ray photon energy.

6- It is found that, the sample that contains $25 \mathrm{~mol} \% \mathrm{Bi}_{2} \mathrm{O}_{3}$ is the best one for attenuating low gamma-ray photon energies.

Glass, American Journal of Physics and Applications 3(6) (2015) 208-214.

2. Ahmed G.S.M., Mahmoud A.S., Salem S.M., and Abou-Elnasr T.Z., Study of GammaRay Attenuation Coefficients of Some Glasses 
Containing CdO, American Journal of Physics and Applications, 3(4)( 2015) 112-120.

3. Bagheri R., Moghaddam A. K., and Yousefnia H., Gamma Ray Shielding Study of Barium-Bismuth-Borosilicate Glasses as Transparent Shielding Materials using MCNP4C Code, XCOM Program, and Available Experimental Data, Nuclear Engineering and Technology 49 (2016) 216-223.

4. Chahine A., Et-Tabirou M. and Pascal J.L., FTIR and Raman spectra of the $\mathrm{Na}_{2} \mathrm{O}-$ $\mathrm{CuOeBi}_{2} \mathrm{O}_{3}-\mathrm{P}_{2} \mathrm{O}_{5}$ glasses, Mater. Lett., 58 (2004) 2776-2780.

5. Chanthima $\boldsymbol{N}$. and Kaewkhao J., Investigation on radiation shielding parameters of bismuth borosilicate glass from $1 \mathrm{keV}$ to $100 \mathrm{GeV}$, Annals of Nuclear Energy 55 (2013) 23-28.

6. Kaewjaeng $S$., Kaewkhao J., Limsuwan P. and Maghanemi U., Effect of $\mathrm{BaO}$ on Optical, Physical and Radiation Shielding Properties of $\mathrm{SiO}_{2}-\mathrm{B}_{2} \mathrm{O}_{3}-\mathrm{Al}_{2} \mathrm{O}_{3}-\mathrm{CaO}-\mathrm{Na}_{2} \mathrm{O}$ Glasses System, Procedia Engineering, 32 (2012)1080 - 1086,.

7. Kaur K., Singh K.J. and Anand V., Structural properties of $\mathrm{Bi}_{2} \mathrm{O}_{3}-\mathrm{B}_{2} \mathrm{O}_{3}-\mathrm{SiO}_{2}-$ $\mathrm{Na}_{2} \mathrm{O}$ glasses for gamma ray shielding applications, Radiation Physics and Chemistry 120 (2016) 63-72.

8. Kirdsiri K., Kaewkhao J., Chanthima N. and Limsuwan P., Comparative study of silicate glasses containing $\mathrm{Bi}_{2} \mathrm{O}_{3}, \mathrm{PbO}$ and $\mathrm{BaO}$ : radiation shielding and optical properties , Ann. Nucl. Energy, 38 (2011) 1438-1441.

9. Manohara S.R., Hanagodimath S.M. and Gerward L., photon interaction and energy absorption in glass: a transparent gamma ray shield, J. Nucl. Mater. 393 (2009) 465-472.

10. Zoulfakar A.M., Abdel-Ghany A.M., Abou-Elnasr T.Z., Mostafa A.G., . El-Bahnaswy S.M. Effect of antimony-oxide on the shielding properties of some sodium-borosilicate glasses, Applied Radiation and Isotopes, 127 (2017) 269. 